\title{
Development of Rotary Magnetoferrite Treatment with Stirrers for Waste Water Treatment Plants to Reduce Excess Sludge
}

\author{
Mahmudul Kabir, ${ }^{1}$ Masafumi Suzuki, ${ }^{1}$ and Noboru Yoshimura ${ }^{2}$ \\ ${ }^{1}$ Department of Electrical and Electronic Engineering, Graduate School of Engineering and Resource Science, Akita University, \\ 1-1 Tegata Gakuenmachi, Akita 010-8502, Japan \\ ${ }^{2}$ Akita University, 1-1 Tegata Gakuenmachi, Akita 010-8502, Japan
}

Correspondence should be addressed to Mahmudul Kabir, kabir@ipc.akita-u.ac.jp

Received 12 September 2011; Accepted 28 September 2011

Academic Editors: P. A. Cooper and I. Lancellotti

Copyright (C) 2012 Mahmudul Kabir et al. This is an open access article distributed under the Creative Commons Attribution License, which permits unrestricted use, distribution, and reproduction in any medium, provided the original work is properly cited.

\begin{abstract}
A large amount of excess sludge is being produced in the waste water treatment plants (WWTPs), which is a serious problem in terms of economical and environmental problems. So, the experiments on reduction of excess sludge are carried out. We have introduced a new approach for reduction of excess sludge by using ferrite particles and permanent magnets. A rotary treatment plant was introduced which showed good possibilities of this method for application in the WWTPs. Stirrers hold a very important role in rotary magnetoferrite treatment as they directly get in touch with ferrite particles and sludge. In this paper, we have shown the relationship between the ferrite particles and stirrers. Again, the treatment was carried out for different amounts of activated sludge which shows that the smaller the amount, the better the treatment of sludge. This knowledge may pave the way for the reduction of excess sludge in WWTPs in practical fields.
\end{abstract}

\section{Introduction}

Activated sludge method is well used in household waste water purification in many countries including Japan. Activated sludge is a group of microorganisms which decompose soluble dirt by oxygen. Despite many good points to use activated sludge in WWTPs, every year a large number of excess activated sludge is produced in the plants. Figure 1 describes the model diagram of WWT system. Waste water, after several treatments, is gathered in "aeration tank" as "influent." Activated sludge is kept there and air is provided. Activated sludge decomposes soluble dirt of "influent." Then, the water is sent to the "settling tank" where water and activated sludge are separated naturally. Finally, purified water is taken out from the plants as "effluent" and, after some tests, removed to the river or sea. Besides purification of the waste water, the number of activated sludge grows in a large amount. It becomes excess to the "aeration tank" and needs to be taken out from the plant. This excess sludge produced in WWTPs is difficult to reuse as it contains a lot of water $[3,4]$. With the help of modern technologies, only
$20 \%$ water can be removed from the activated sludge. For a sustainable society, this excess sludge must be controlled. Many research works are carried out in the treatment of excess sludge $[1,3-8]$. Another approach is to reduce excess sludge by various methods such as ozone treatment, mill treatment, and thermal treatment [1, 3-8]. In WWTPs, these treatment plants are set up in the return sludge line. The treated sludge is taken to the aeration tank where untreated sludge decomposes it and thus the amount of excess sludge can be reduced [1]. We have developed an innovative method for reduction of excess sludge by using ferrite particles and permanent magnets [9-11]. The cells of bacteria and microorganisms are broken up by the motion of ferrite particles in activated sludge. Two miniature WWTPs carried out in the conventional activated sludge (CAS) method were used to evaluate the magnetoferrite treatment method which showed that an average of $42 \%$ of excess sludge reduction was possible with our system. The system was checked by the extended aeration (EA) method, and there was found no excess sludge by using the magnetoferrite treatment. However, these tests were carried out in laboratory scale. 


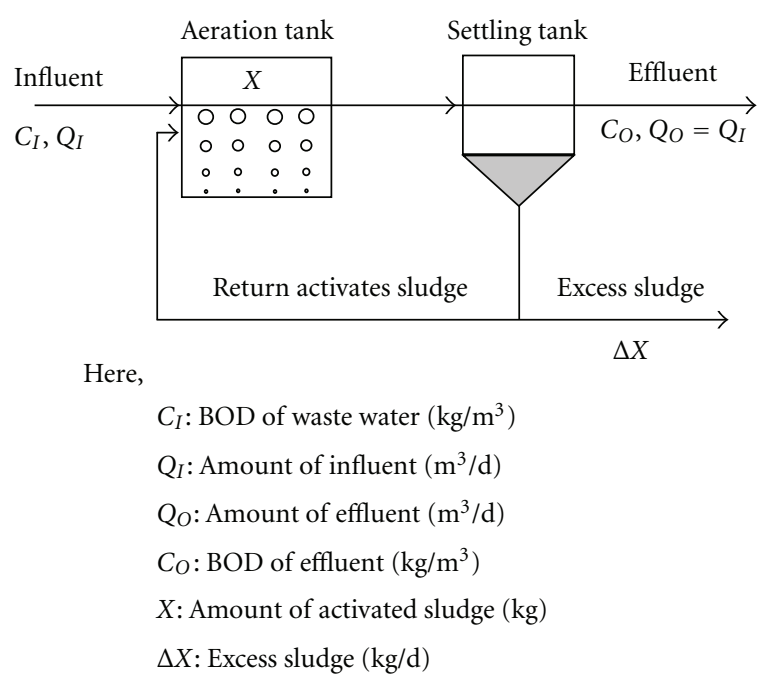

Figure 1: Model diagram of WWT system [1].

The system should be verified with real WWTPs which need to build larger magnetoferrite treatment plants. To make larger plants, we need a vast land and large amount of electric power which is not economical. It can be understood that magnetoferrite treatment needs improvement for practical use. We have tried to solve these problems by making a rotary magnetoferrite treatment plant [2]. A rotary plant can treat a large amount of activated sludge at a time. It can easily be set in the real WWTPs and run easily. We examined the effectiveness of magnetoferrite treatment in the reduction of excess activated sludge with two miniature WWTPs which can be found in detail in another paper [2]. This plant used a motor, a rotor, magnets, and a container in which ferrite particles and activated sludge were kept. A round shaped stirrer with a metal plate in it was in the container. The plant could sterilize $90 \%$ of $300 \mathrm{~mL}$ of sludge at a time. In the reduction tests, the rotary plant showed a very good effect to the activated sludge to control the excess sludge. Only an application of $4 \mathrm{~h} / \mathrm{d}$ of magnetoferrite treatment showed about $72 \%$ of reduction of excess sludge in our laboratory miniature WWTPs. Thus, it can be useful to reduce a large amount of sludge of the WWTPs.

This paper describes the method of rotary magnetoferrite treatment and its mechanism. To improve the effectiveness of the rotary treatment plant, we made a smaller plant with a motor, rotor, and magnets. Ferrite particles were used to make collisions with activated sludge. The sludge was taken into a treatment container with ferrite particles and a stirrer for the treatment. Reduction of sludge is related with the treatment of the activated sludge. Therefore, sterilization of the bioorganisms was observed by the treatment for certain conditions. Stirrers are very important in this method. Several sizes of stirrers were reviewed. We have discussed the increase of the effectiveness of this method. The distribution of magnetic flux and the amount of ferrite particles are other key parameters of this method. We have shown that the necessary amount of ferrite particles is dependent on the

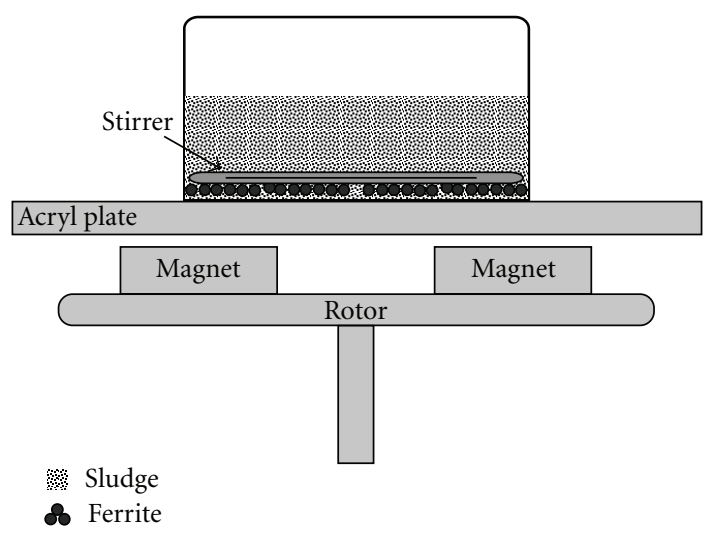

FIgure 2: The model diagram for the rotary plant [2].

size (radius) of the stirrer. This knowledge will help to apply rotary magnetoferrite treatment plant in field tests.

\section{Methods}

A rotary plant has a rotor, a container to treat sludge, and magnets. The schematic diagram can be seen in Figure 2. The rotary plant is designed from the previous paper treatment plant [2]. A smaller miniature plant is useful especially in laboratory environment. A larger plant needs larger amount of sludge to treat, which is not always available in a laboratory. For example, our laboratory has miniature WWTP whose capacity is about $7 \mathrm{~L}$ only. So, we made a smaller plant to perform several experiments in order to increase the efficiency of the rotary plant. The diameter of the rotor is $7.2 \mathrm{~cm}$. Doughnut-type magnets were put together on the rotor. 8 magnets were bundled in a row. Each magnet is $2.8 \mathrm{~cm}$ in diameter, and they have a hole of $1.4 \mathrm{~cm}$ in each magnet. The width of a magnet is $2 \mathrm{~mm}$. 16 magnets were used in 2 rows. They were fixed by a metal plate on the rotor. The average magnetic flux of the magnets is $40-$ $50 \mathrm{mT}$ at the center on the acryl plate. The rotor is connected to a shaft of a motor (PS 540-401, Oriental Motor Co.). The speed range of the motor is $90-1400 \mathrm{rpm}$. The speed of the rotor as well as the magnets can be controlled by this motor. Up above the rotor, an acryl plate is set to hold the sludge container. This plate is fixed by 4 nuts in such a way that the distance between the magnets and the acryl plate as well as the container can be changeable in vertical direction. The size of this treatment pot is $60 \times 20 \mathrm{~mm}$. Its capacity is $50 \mathrm{~mL}$. This container is made of plastic (PVC). The container is fixed on the acryl plate by adhesive tape. In the container, ferrite particles and activated sludge are kept. The rotor moves with the motor and thus a moving magnetic field can exist around the acryl plate. The ferrite particles move or try to move with the magnets. A certain speed of the motor can possibly drag the ferrite particles in such a way that they can crush the activated sludge by grabbing them in the gaps made by the particles. The size of the gaps can be gained by the diameter of the ferrite particles $[12,13]$. For a value of diameter $d$ for ferrite particles, the gap made by 


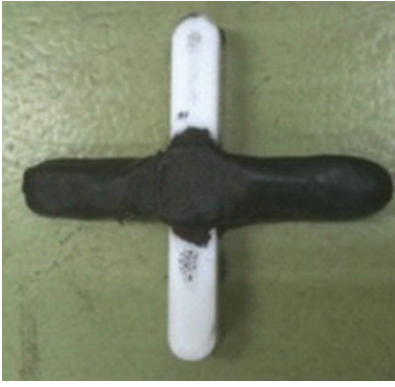

(a) cross type

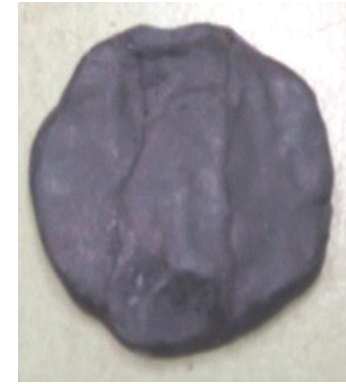

(b) circle type
FIgURE 3: Photos of stirrers.

ferrite particles is $d \sqrt{ }(3 / 2)-d$. Thus, the size of the ferrite particles can be determined. From the previous experiments, the size of the ferrite particles that can be effective for the treatment was less than $50 \mu \mathrm{m}[9,10]$. The same type of ferrite particles were used in this research work.

On the reservoir, a stirrer is kept so that the collisions between ferrite particles and activated sludge can occur easily. The shape and size of the stirrer is very important for this treatment. 2 types of stirrers were made by using free plastic (Daicel FineChem. Co. Ltd., Japan). Free plastic is a kind of plastic whose melting temperature is $60^{\circ} \mathrm{C}$. Figure 3 provides the photos of the stirrers. The stirrers were tested by rotary plant. From the experimental results, the appropriate type of stirrer was selected.

The rotary magnetoferrite treatment is using magnetic materials such as ferrite particles and stirrer. Their movement is controlled by magnets. The magnetic flux distribution was also measured by a Gauss meter (GM04, HIRST) to understand the movements of ferrite particles.

First, we will discuss the shape of the stirrers. We proposed 2 types of stirrer and performed the magnetoferrite treatment. Then different sizes of stirrers with different amounts of ferrite particles were chosen for the best result. Figure 5 shows the shape and size of the larger stirrer. We also checked the relation of the amounts of activated sludge and the stirrer. First we will discuss the stirrers. They are as follows.

2.1. Cross-Type Stirrer. These are cross-type stirrers. A magnetic stirrer is wrapped with free plastic.

2.2. Circle-Type Stirrer. This is a circle-type stirrer with a small magnet in the circle type. The collision area is larger compared to the cross type stirrer. The diameter of this stirrer was $52 \mathrm{~mm}$.

All the experiments were carried under the following processes.

(1) Activated sludge was taken into a beaker and its mixed liquor suspended solid (MLSS) was adjusted at $3000 \mathrm{mg} / \mathrm{L}$ by an MLSS meter (SS-5F, KRK, Japan).

(2) The viable cell number of the activated sludge was determined by Easicult TTC (Diagnostica Co.).
(3) The chemical oxygen demand (COD) of the supernatant liquid of activated sludge was measured by a COD meter (UV-M3, Sky Science, Japan).

(4) In the treatment container (i.e., plastic reservoir), a fixed amount of sludge, ferrite particles, and stirrer were taken. The pot was well sealed so that the sludge could not leak out from it.

(5) This pot and the sludge were taken under rotary magnetoferrite treatment for $1 \mathrm{~h}$ with $150 \mathrm{rpm}$.

(6) After the treatment, the treated sludge was taken out of the pot and the viable cell was counted by Easicult TTC. The viable cell coefficient (VCC) was calculated by using the following equation:

VCC $[\%]$

$$
\begin{aligned}
& =\frac{\text { viable cell number of treated activated sludge }}{\text { viable cell number of initial stage of the activated sludge }} \\
& \quad \times 100 \text {. }
\end{aligned}
$$

(7) The MLSS of the treated sludge was measured by a moisture balance (MOC-120 H, Shimadzu, Japan).

(8) After the treatment, the treated sludge was taken out of the pot and the supernatant liquid was separated by a cyclone separator (Marusan, Japan). Then, the COD of the supernatant liquid was measured.

The shape of the stirrer was determined first for the rotary treatment system. And then we performed several experiments with different amounts of ferrite particles with 3 different stirrers. We proposed a relationship between the ferrite particles and the size of stirrers. We also investigated different amounts of activated sludge for a stirrer and ferrite particles.

\section{Results and Discussions}

3.1. Magnetic Flux Distribution. Magnetic flux distribution of the magnets was measured for the treatment system. The Hall probe of the Gauss meter was moved on the acryl plate to the $X-Y$ direction and then the magnetic flux of the magnets measured. The distance between the acryl plate and the magnets was $1 \mathrm{~cm}$. Figure 4 shows the magnetic flux distribution of the magnets. The dotted circle line indicates the position of the treatment pot on the acryl plate.

3.2. Shape of Stirrer. Sterilization was performed for the 2 types of stirrers with $5 \mathrm{~g}$ of ferrite particles. After each test, the viable cell and COD of supernatant liquid were measured. Table 1 shows the results of these experiments. Sterilization was achieved for both of the stirrers. When sterilization progresses, the disruption of sludge is also achieved which plugs into the increase of COD of the supernatant liquid of the treated activated sludge. From Table 1, it can be seen that the viable cell was found to be less after the test with circle stirrer compared to the cross-type stirrer. However, 
TABLE 1: Experimental results for 2 stirrers.

\begin{tabular}{lccccc}
\hline \multirow{2}{*}{ Stirrer } & \multirow{2}{*}{ Ferrite particles $(\mathrm{g})$} & \multicolumn{2}{c}{ Viable cell $(\mathrm{CFU} / \mathrm{mL})$} & \multicolumn{2}{c}{ COD of supernatant liquid $(\mathrm{mg} / \mathrm{L})$} \\
& & Control & After treatment & Control & After treatment \\
\hline Circular & 5 & $10^{6}$ & $10^{4}$ & 13.6 & $\mathbf{1 2 5 . 8}$ \\
Cross & 5 & $10^{6}$ & $\mathbf{1 0}^{5}$ & 14.1 & $\mathbf{1 8 0 . 0}$ \\
Circular & $\times$ & $10^{7}$ & $\mathbf{1 0}^{\mathbf{7}}$ & 33.5 & $\mathbf{6 7 . 3}$ \\
$\times$ & 5 & $10^{7}$ & $\mathbf{1 0}^{\mathbf{7}}$ & 18.6 & $\mathbf{4 5 . 5}$ \\
\hline
\end{tabular}

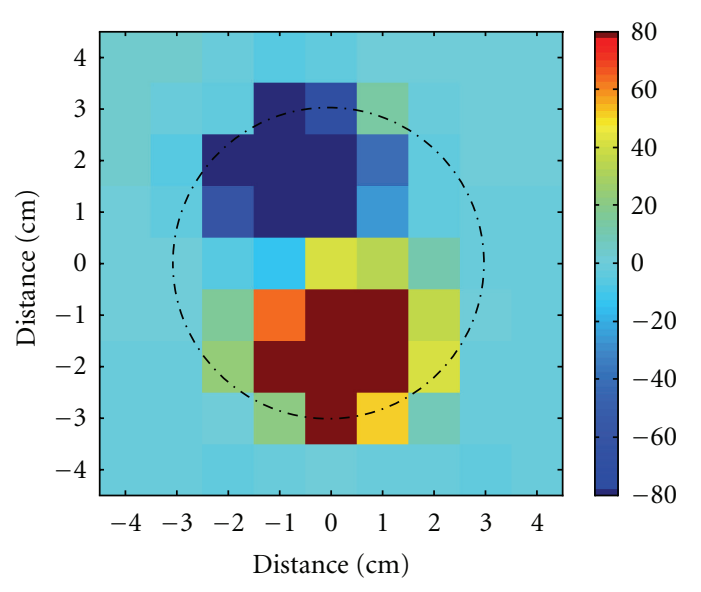

FIGURE 4: Magnetic flux distribution of the miniature rotary plant.

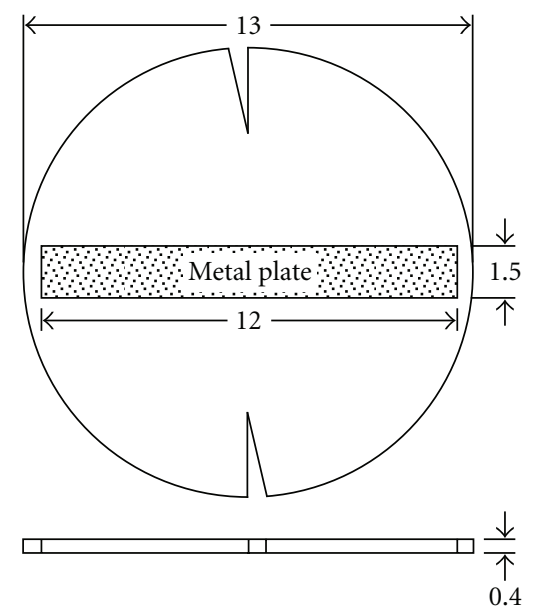

Figure 5: The diagram model of the stirrer [2].

the value of COD for cross-type stirrer was larger than that of circle-type stirrer. For a small amount of activated sludge, the collision with the cross-type stirrer and sludge is larger, but it becomes smaller with the increase of sludge and a larger stirrer of the same shape. Again, a test was performed without any stirrer and another was performed with ferrite particles but no stirrer. Both these results show that neither ferrite particles nor stirrer alone can sterilize the activated sludge. From these results, we decided to use the circle-type stirrers for further experiments.
3.3. Ferrite Particles and the Size of Stirrers. We investigated the relation between the size of stirrer and the amount of ferrite particles for rotary treatment plants. First, the sterilization tests were performed with different amounts of ferrite particles for the diameter of $52 \mathrm{~mm}$ of circle stirrer. The chosen ferrite particles were $2.5,5,8,10$, and $15 \mathrm{~g}$ for the treatment. The treatments were observed for $150 \mathrm{rpm}$ of motor speed. The amount of sludge was $15 \mathrm{~mL}$, and the size of the treatment container was $60 \times 20 \mathrm{~mm}$. After each treatment of sludge, the viable cell, MLSS, and COD were measured. The VCC was determined for each treated sludge with different ferrite particles. The value of VCC was $10 \%$ for $2.5 \mathrm{~g}$ of ferrite particles but for another amount of ferrite particles it was $1 \%$. The initial value of MLSS for the sludge was $3000 \mathrm{mg} / \mathrm{L}$ as described in the method of this paper. The value of MLSS decreased with all the ferrite particles except for $2.5 \mathrm{~g}$ of ferrite particles. The disrupted sludge increased the values of COD of the supernatant liquid. In the previous section, we have seen that both ferrite particles and stirrer are essential for the sterilization for a rotary treatment plant. We tried to detect a relation between the amounts of ferrite particles and the size of the stirrer. The surface area of this stirrer is divided by each amount of ferrite particles. The values of the calculated relation are 1.2, 2.4, 3.8, 4.7, and $7.1 \mathrm{~kg} / \mathrm{m}^{2}$ for $2.5,5,8,10$, and $15 \mathrm{~g}$ of ferrite particles, respectively. From this experiment, it can be understood that the range of this relation is $2.4-7.1 \mathrm{~kg} / \mathrm{m}^{2}$. This relation was checked with other sizes of stirrers of the same shape.

Another stirrer was made by the same process described in method with the diameter of $62 \mathrm{~mm}$. Then, this relation was applied for the appropriate ferrite particles for this stirrer. Ferrite particles were calculated in such a way that they fit with the same range of the previous experiment. They were 7.1 and $11.4 \mathrm{~g}$ for 2.4 and $3.8 \mathrm{~kg} / \mathrm{m}^{2}$. With these ferrite particles, we performed the treatment of activated sludge and carried out the same measurements described early. The results were very good for both sterilization and disruption of activated sludge. Other amounts of ferrite particles which can meet the condition (i.e., $2.4-7.1 \mathrm{~kg} / \mathrm{m}^{2}$ ) were chosen for the treatment. They were $15.0\left(5.0 \mathrm{~kg} / \mathrm{m}^{2}\right)$ and $19.2 \mathrm{~g}$ $\left(6.4 \mathrm{~kg} / \mathrm{m}^{2}\right)$. Again, for the same kind of experiments, the sterilization and disruption of activated sludge were achieved. It proved our hypothesis that the appropriate ferrite particles for a stirrer can be calculated by the surface area of a stirrer (i.e., amount of ferrite particles/surface area of the stirrer $=2.4-7.1 \mathrm{~kg} / \mathrm{m}^{2}$ ). If the radius of a stirrer is $r[\mathrm{~m}]$, then the appropriate amount of ferrite particles 

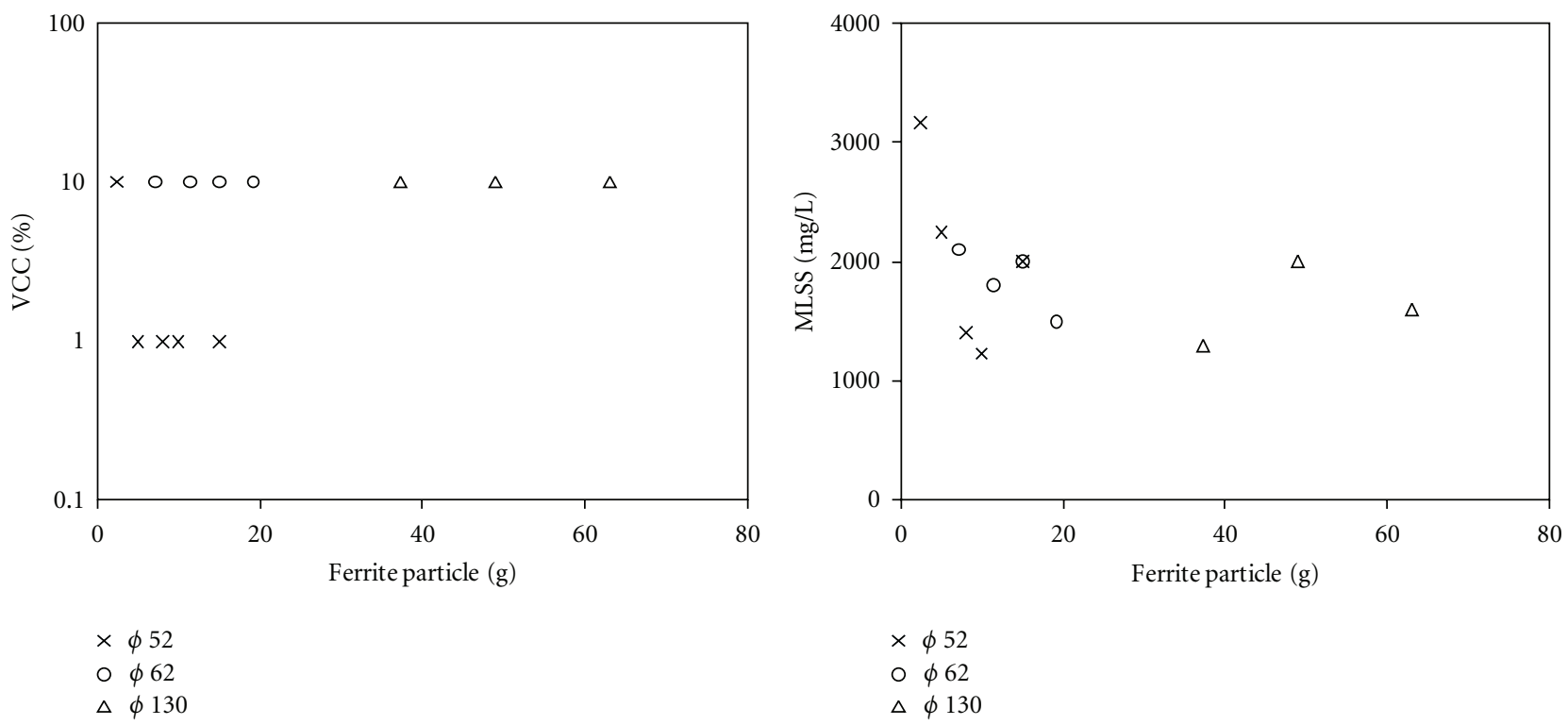

(a) VCC

(b) MLSS

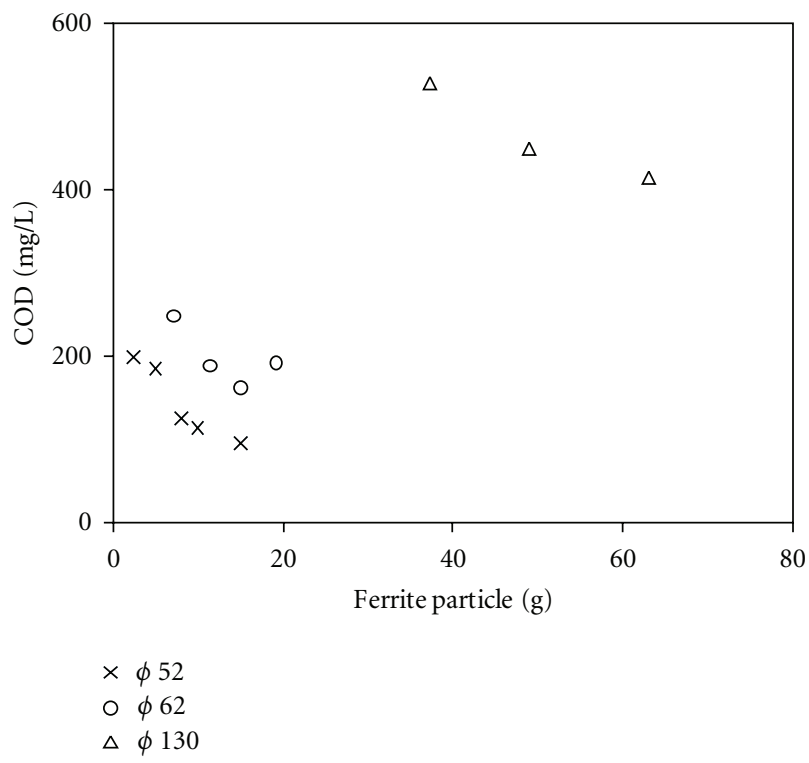

(c) COD of supernatant liquid

FIGURE 6: Experimental results with different sizes of stirrers.

(e.g., $m[\mathrm{~kg}]$ ) should meet the following relation: $m / \pi r^{2}=$ $2.4-7.1 \mathrm{~kg} / \mathrm{m}^{2}$.

Finally, we checked our idea with a larger stirrer whose diameter was $130 \mathrm{~mm}$. This stirrer was used in the reduction test of the activated sludge at laboratory scale described in another paper [2]. The ferrite particles were chosen as they met the previous relation (i.e., $m / \pi r^{2}=2.4-7.1 \mathrm{~kg} / \mathrm{m}^{2}$ ). The treatment system can be found in another paper [2]. The treatment container was $170 \times 50 \mathrm{~mm}$ and it could contain $870 \mathrm{~mL}$ of sludge at a time. The activated sludge was $100 \mathrm{~mL}$. The ferrite particles were 37.2, 48.9, and $63 \mathrm{~g}$. Again, the same experiments were performed with these ferrite particles. The results with other stirrers can be seen in Figure 6 .
Figure 6(a) represents the sterilization effect of these experiments while Figures 6(b) and 6(c) show the values of MLSS and COD of the treated sludge, respectively. Figure 6(a) is a semilogarithmic graph which shows the calculated VCC of the experimental results. For both experiments, sterilization was achieved.

The COD values of supernatant liquid from the treated sludge were larger for the larger stirrer compared to other stirrers. It is due to the larger amount of activated sludge (i.e., $100 \mathrm{~mL}$ ) compared with others.

From these experiments, we will generalize this relation of ferrite particles and stirrer. For 2 stirrers of different radii (i.e., $r 1, r 2[\mathrm{~m}]$ ), if the appropriate ferrite particles are $m 1$ 


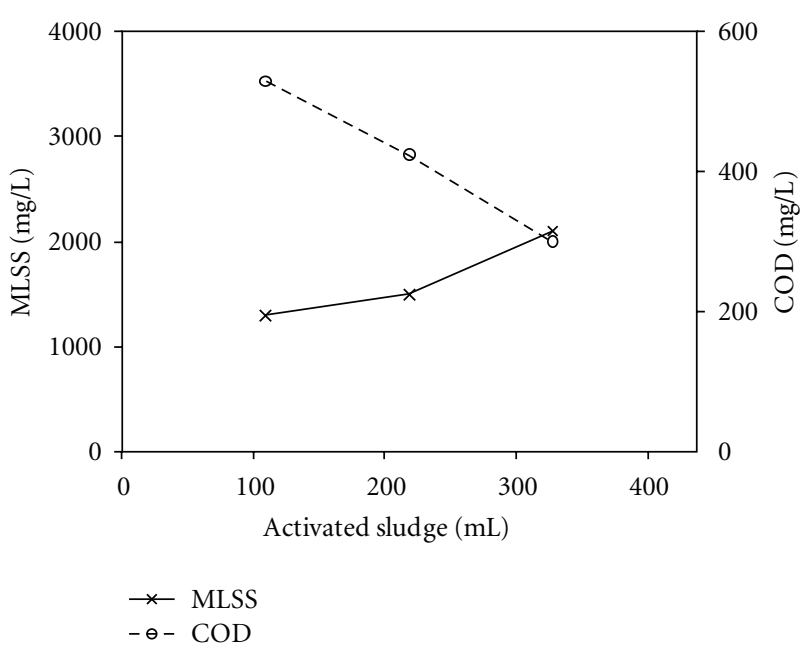

FIGURE 7: The experimental results of different amounts of activated sludge with $37.2 \mathrm{~g}$ of ferrite particles.

and $m 2[\mathrm{~kg}]$, then the following equation shows the relation between them:

$$
\frac{m 1}{\pi r 1^{2}}=\frac{m 2}{\pi r 2^{2}}=\text { constant number } \ldots .
$$

Equation (2) can be rewritten as follows:

$$
m 1: m 2=r 1^{2}: r 2^{2} \ldots
$$

The relation can be applied to make a larger treatment plant of excess activated sludge.

3.4. Amount of Activated Sludge. Different amount of activated sludge was treated with the larger stirrer with $37.2 \mathrm{~g}$ of ferrite particles. The treatment container was $170 \times 50 \mathrm{~mm}$. This container was chosen as it could use larger amount of activated sludge at a time. The conditions of this experiment are

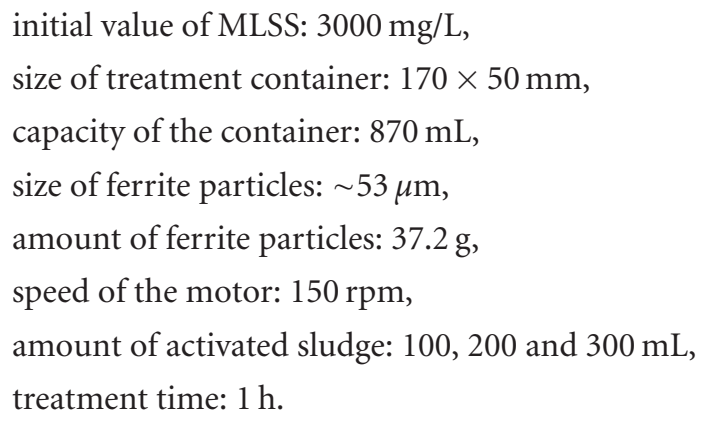

With the above conditions, the rotary magnetoferrite treatment was applied for each amount of the activated sludge. After the treatment, the viable cell was measured by Easicult TTC and gradually their VCC was calculated by (1). We will not show the data of VCC but it was $10 \%$, which indicates the sterilization for the experiments. The MLSS of the treated sludge and the COD of the supernatant liquid were also measured. The measured data were plotted

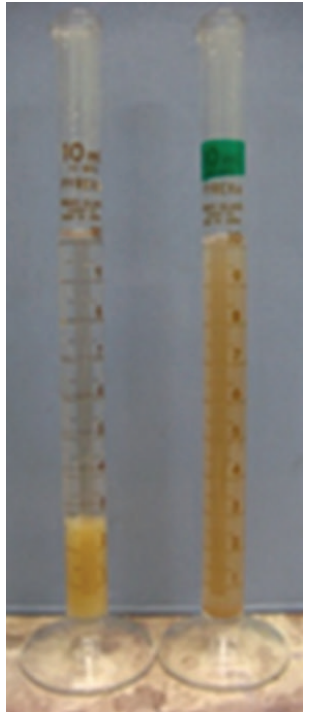

(a) $100 \mathrm{~mL}$

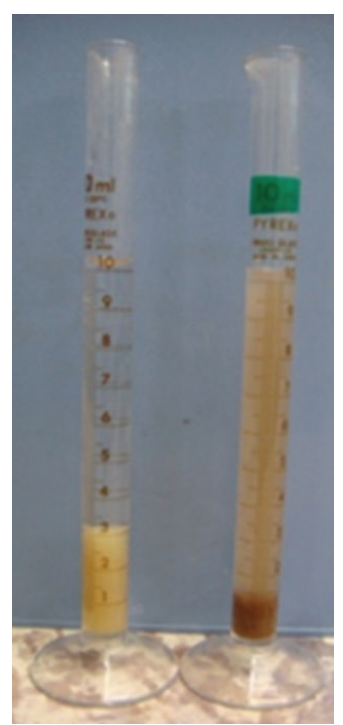

(b) $300 \mathrm{~mL}$
FIGURE 8: Sedimentation of treated and untreated sludge according to the volume of activated sludge.

in Figure 7. It can be seen that the disruption of sludge was better for a definite amount of ferrite particles compared with larger amount of activated sludge. This method can only be fruitful when the sludge comes underneath the stirrer. That is the reason for the larger disruption of smaller quantity of activated sludge. The larger disruption plugs into the larger solubilization of the activated sludge which can be verified by the values of COD of supernatant liquid after the treatment. The disruption of sludge is megascopic, too. We took $10 \mathrm{~mL}$ of treated and untreated activated sludge and kept them $30 \mathrm{~m}$ to settle naturally. Figure 8 provides 2 snapshots for the sedimentation situation of treated and untreated sludge. $10 \mathrm{~mL}$ of treated and untreated sludge was kept for 30 minutes in 2 graduated cylinders. It can be seen that the disruption of sludge was better in $100 \mathrm{~mL}$ of activated sludge compared to $300 \mathrm{~mL}$ of activated sludge. Rotary treatment plant can treat only the activated sludge which gets contact with the stirrer underneath it.

\section{Conclusion}

In order to increase the effect of rotary treatment plant for practical use in the WWTPs, we performed several experiments with different sizes of stirrers and ferrite particles. Stirrers were made by free plastic, and they were used for certain amounts of activated sludge and ferrite particles with rotary treatment plant. Our experiments showed the following results.

(1) Both ferrite particles and stirrer are essential for rotary treatment system.

(2) To make a larger treatment plant of activated sludge, the appropriate ferrite particles can be determined easily from the radii of the stirrers. The ratio of 
the necessary ferrite particles is equal to the ratio of the square of the radius of the related stirrers.

(3) Rotary treatment plant is capable of treating only the sludge which is directly related to the stirrer and ferrite particles.

These facts may pave the way for the reduction of excess sludge in WWTPs in practical fields. However, the larger rotary plant should be tested with WWTPs for long-term use.

\section{References}

[1] Y. Miyoshi, Ideas and Techniques of Sewage and Wastewater Treatment, Ohmsha, Tokyo, Japan, 2006.

[2] M. Kabir, M. Suzuki, and N. Yoshimura, "Reduction of excess activated sludge by ferrite particles: methods for practical use," International Journal of the Society of Materials Engineering for Resources, vol. 17, no. 2, pp. 120-125, 2010.

[3] Y. Wei, R. T. Van Houten, A. R. Borger, D. H. Eikelboom, and Y. Fan, "Minimization of excess sludge production for biological wastewater treatment," Water Research, vol. 37, no. 18, pp. 4453-4467, 2003.

[4] T. Yoshida, Ed., Technologies for Minimization of Sludge and Reduction of Sludge, NTS, Tokyo, Japan, 2000.

[5] W. W. Eckenfelder and P. Grau, Eds., Activated Sludge Process Design and Control: Theory and Practice, Technomic Publishing, Lancaster, UK, 1998.

[6] Y. Sawada, S. Nagashima, T. Uchida et al., "Basic study on sludge concentration and dehydration with ultrasonic exposure," Japanese Journal of Applied Physics, vol. 44, no. 6, pp. 4678-4681, 2005.

[7] H. Yasui and M. Shibata, "An innovative approach to reduce excess sludge production in the activated sludge process," Water Science and Technology, vol. 30, no. 9, pp. 11-20, 1994.

[8] A. Sano, Y. Bando, K. Yasuda, M. Nakamura, A. Senga, and E. Kiyokawa, "Enchancement in biodegradability of excess sludge by using a centrifugal vibration mill," Journal of Chemical Engineering of Japan, vol. 38, no. 6, pp. 446-449, 2005.

[9] M. Kabir, M. Suzuki, and N. Yoshimura, "Reduction of excess sludge by ferrite particles," Japanese Journal of Water Treatment Biology, vol. 43, no. 4, pp. 189-197, 2007.

[10] F. S. G. Einshlag, Ed., Waste Water Treatment and Reutilization, INTECH, Vukovar, Croatia, 2011.

[11] M. Kabir, M. Suzuki, and N. Yoshimura, "Reduction of excess sludge by magneto-ferrite treatment: observation on lab scale WWTPs," IEEJ Transactions on Electrical and Electronic Engineering, vol. 4, no. 4, pp. 584-586, 2009.

[12] N. Yoshimura, M. Suzuki, and T. Sato, "Microbic handling by means of electricity and magnetism," Journal of the Institute of Electrostatics Japan, vol. 18, no. 1, pp. 11-17, 1994 (Japanese).

[13] Y. Murayama, T. Itoh, M. Suzuki, and N. Yoshimura, "Effect of magnetic field and ferrite treatment on various organism," Transactions of the Institute of Electric Engineers of Japan, vol. 113A, no. 8, pp. 594-595, 1993 (Japanese). 

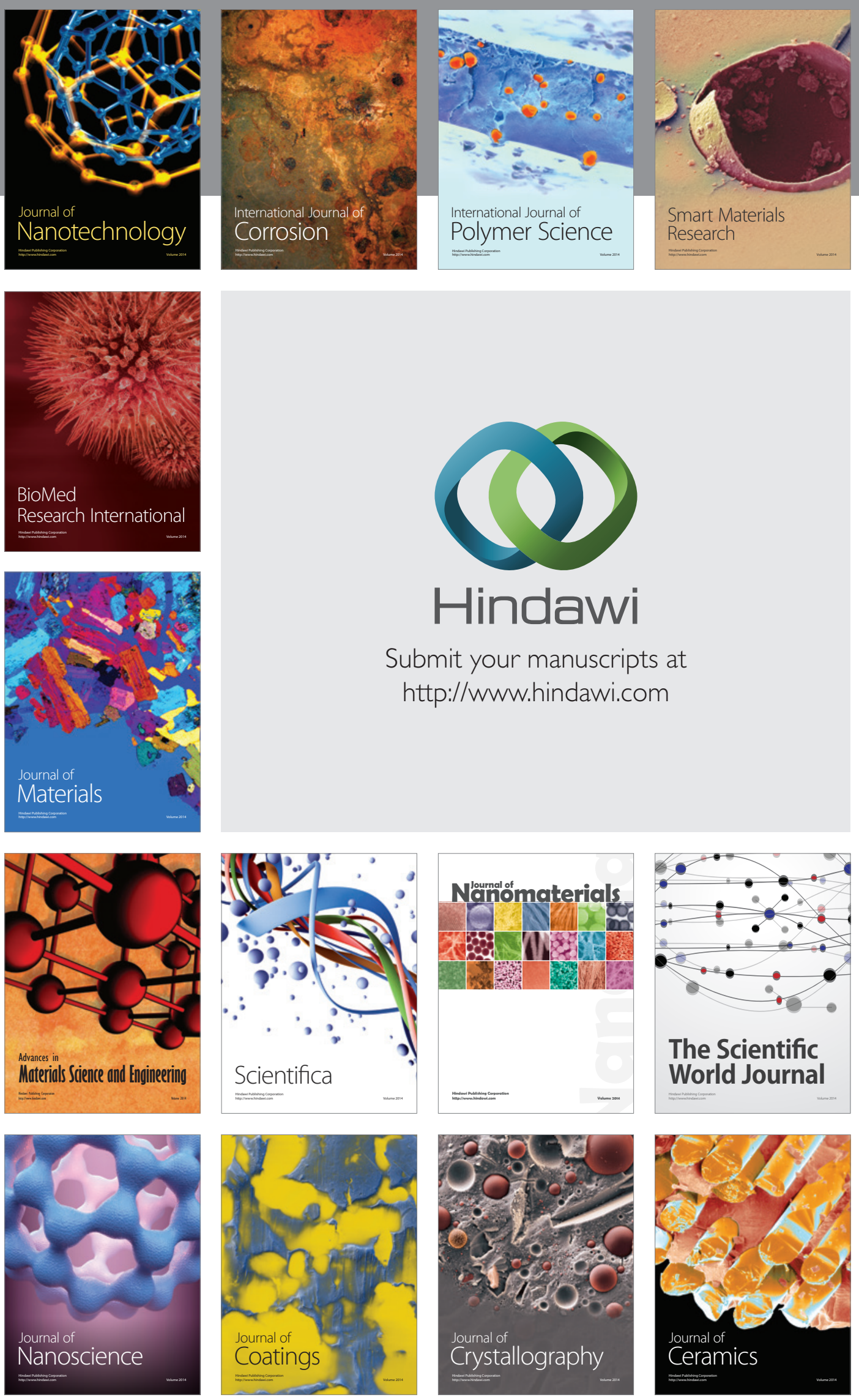

The Scientific World Journal

Submit your manuscripts at

http://www.hindawi.com

\section{World Journal}

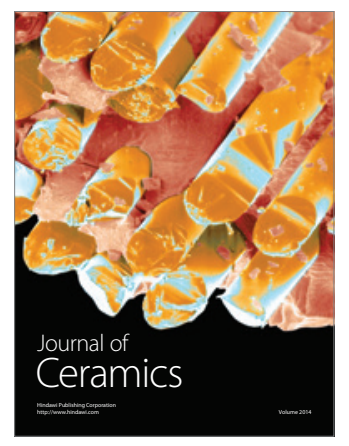

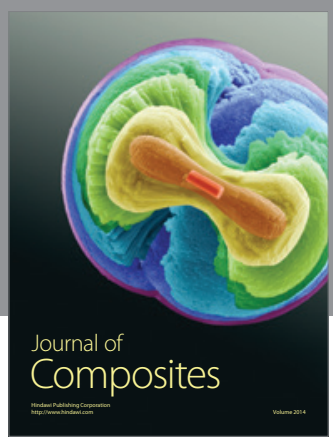
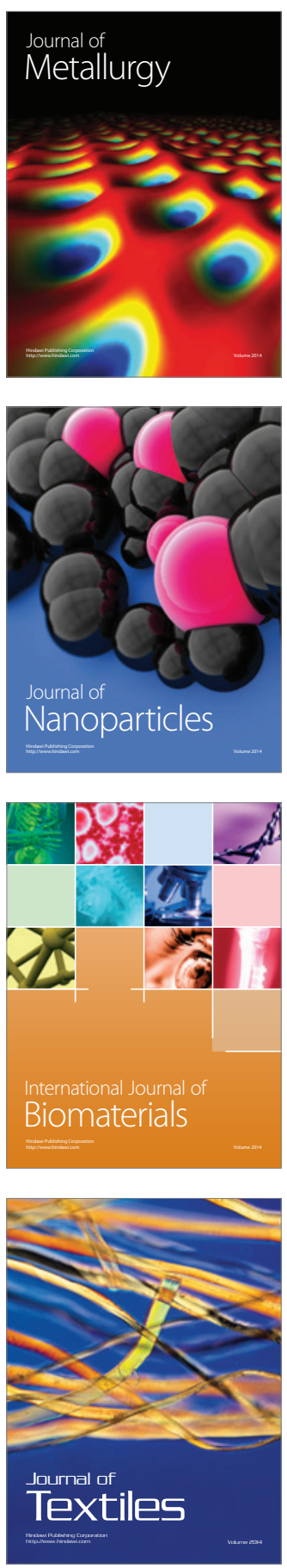